\section{Foreigners' tenure at Tsukuba}

SIR-I should like to add a gloss to Alun Anderson"s fair report on the "turmoil over treament of foreign staff" (Nature 10) October. p.465) at Tsukuba University. self-proclaimed champion of the internationalization of university education in Japan.

Four foreign staff members. including myself, expected to be given long-term contracts not because "some supporters made affirmative responses" to them, as Tsukuba`s president. Nobiyuki Fukuda. says, but because the due process for their appointments had been put in train: the vice-president in charge of education, $e x$ officio member of the personnel committee that makes final decisions in personnel matters, first ascertained the need for our posts at the departmental level, then discussed his proposal to give us long-term contracts at a meeting of the president and the five vice-presidents, none of whom voiced any opposition. Thereupon he instructed the department heads to let us know that we were scheduled to get tenure. The department heads prepared the formal applications to be submitted to the personnel committee. I therefore think that our expectations were not "extremely strange" as Mr Fukuda believes, but only reasonable. What is strange is that the final authority on personnel matters was not given a chance to make its decision as neither the departmental applications nor the supporting proposition of the vicepresident were considered by a meeting of the personnel committee - apparently both were blocked when the vicepresident was sacked.

While it is true that there is no final definition of "internationalization", I think there is agreement on certain ingredients that it must contain, such as nondiscrimination on grounds of nationality, transparency and minimum civility. Tsukuba University is still in want of all of them. I am afraid. Anderson amply illustrated that foreigners at Tsukuba are not treated "just like anyone else". It might be added that Tsukuba did not avail itself of the opportunity the new law offers to give tenure to foreigners. For foreigners at Tsukuba, "tenure" means just 5-year contracts, while every Japanese staff member gets real tenure from the start. Foreign lecturers have to carry a teaching load of 12 hours per week whereas their Japanese colleagues average five.

The rule limiting employment of foreigners without tenure to four years resulted from the unwillingness of university authorities to speak their mind clearly. Not all foreign lecturers have always performed their task satisfactorily. The university therefore introduced a system grading each foreigner (but no Japanese) each year as $\mathrm{A}, \mathrm{B}$ or $\mathrm{C}$. Yet rather than tell the $\mathrm{Cs}$ to improve or leave, all lecturers had to quit, the As along with the Cs. The announcement was made in writing. with no explanation.

"Inexplicable silence followed by brazen behaviour". a Japanese attitude regarded by many Westerners and Japanese as a serious obstacle to internationalization, also characterized the recent events at Tsukuba that Anderson described. No wonder then that Tsukuba is seen as becoming more parochial rather than internationalized. To dismiss this view as "nonsense". as Mr Fukuda does. does little to solve the problem.

Marciarete Sawada

Namiki 3-518, Sakuramura.

Ibaraki 305, Japan

\section{Reputable PhDs}

SIR- A $\mathrm{PhD}$ is supposed to be a training in research" says Beverly Halstead ( $\mathrm{Na}$ ture 316,$760 ; 1985)$ and therein lies his problem. I suspect that some proportion of every thesis (for example the research training part) will not meet the standards of the existing avenues for publication. That is not to say that some of this proportion would not be useful to someone embarking in that particular area of research. Thus there exists a case for making theses, in their entirety, more readily available globally through some other means (for example microfiche).

Attempting to distinguish major from non-major contributions to science would be headache enough, but differentiating between reputable and non-reputable journals is a job I leave for Beverly Halstead. I look forward to his published list appearing in these columns.

Department of Botany,

Jonathan A. KEOGH

University of Botany,

University of Otago,

\section{Dunedin}

New Zealand

\section{Units are for people}

SIR-Although no system is proof against mistakes, spectacular events, such as the apparent misprogramming of a spaceshuttle computer (Nature 315, 702; 1985), highlight the usefulness of an agreed universal system of units. D.C. Jolly (Nature 316, 480; 1985) enters an impassioned case for the foot, pound, second system, as an alternative to SI and pleads for a counterrevolution. W.G. Rees (Nature 317, 10; 1985) has suggested an ingenious system which differs from the foot, pound, second system by a possibly tolerable amount, such that $c, G$ and $4 h$ become exact multiples of his base units.

Unfortunately, his suggestion is impractical since, for example, we cannot yet measure all of the fundamental constants and atomic phenomena with the required accuracy. Indeed, as we do so, the SI units too will incorporate the fact for the Conférences Générales des Poids et Mesures will revise the recommended definitions of the base units accordingly, as they have with the second and metre - but without altering their size.

While it is tempting to argue for a change to a "natural" system of units, we ought to recall that part of the appeal of the c.g.s. system to our nineteenth century forebears stemmed from its use of "natural" quantities associated with our planet. Who can be sure that the fundamental constants $e, c, h, G$ and so on will not have been replaced by an ever deeper set by the end of the next century? Moreover, a system only appears natural if the units are appropriate to the discipline with which the proposer is most familiar - what is "natural" for the physicist is not necessarily so for the biologist, chemist, artisan or "man in the street".

We might yet, if we chose, be able to recycle some of our earlier units instead. for $G$ is near enough unity in the Gunter link, troy grain and lunar month system of units, and the Planck constant essentially 1 attoleague ${ }^{2}$ megascruple. centiweek ${ }^{-1}$ (British nautical leagues, apothecaries scruples and sidereal weeks). Professor Kenneth Meyer, at the University of Cincinnati, has shown how unit conversion tables (in the Handbook of Chemistry and Physics and elsewhere) together with a microcomputer allow such combinations to be found - even an exact one by an undetectable massaging of the magnitude of the earlier unit! I suggest though that readers wait for the forthcoming CODATA evaluation of the recommended "best values" of the fundamental physical constants before searching for the best such combination of earlier units to six decimal places!

National Physical Laboratory

B.W. Petley

Teddington,

Middlesex TW11 OLW, UK

\section{Sir Henry Wellcome}

SIR-In the article on the Wellcome Trust and Foundation (Nature 24 October, p.662), you refer to them as being set up under the will of Sir Henry Dale. I believe that it was Sir Henry Wellcome who in his will created these institutions.

As a young prescriptions clerk in Rochester, Minnesota, Wellcome was encouraged and supported by Dr W.W. Mayo to improve his education and not to be satisfied with his position. Mayo had been taught chemistry by John Dalton before emigrating to the United States. His sons, William and Charles Mayo, created the Mayo Clinic.

LARS BREIMER

Department of Chemical Pathology, Royal Postgraduate Medical School,

Hammersmith Hospital,

Ducane Road,

London W12 OHS, UK 